\title{
Incorporating audio feedback to enhance inclusivity of courses
}

\author{
Sue Wilkinson \\ Cardiff Metropolitan University, UK
}

\begin{abstract}
Higher education institutions (HEIs) are under increasing pressure to provide inclusive courses that are accessible to all students, and with the percentage of disabled learners in higher education increasing each year, this has become a key factor in institutional strategies and teaching and learning agendas. This paper briefly highlights the issues that have led to the need for alternative methods of feedback, and offers support for why audio feedback is one way of bridging the gap between learner engagement and tutor feedback. Audio feedback is an alternative method of communicating advice to students that not only benefits disabled learners, but also non-disabled learners, as well as tutors.
\end{abstract}

Keywords: inclusivity; learning development.

Recent statistics reveal that the percentage of disabled learners in higher education is increasing (62,865 full time undergraduate in 2010/11 compared to 56,580 in 2009/10 and 52,815 in 2008/09, HESA, n.d., table T7). With this in mind, the need for courses to be accessible and inclusive has never been so crucial. Not only will an inclusive course reduce the need for adjustments to be made for disabled learners, it will also reduce the observable differences between disabled and non-disabled students in terms of their learning environment and involvement in their courses.

Traditional educational structures and approaches still largely prevail, and it is believed by some that this is influential in preventing Higher Education Institutions (HEIs) achieving social inclusion (Scott, 2006). Changes need to be made for HEls to fully involve themselves in the widening participation and social inclusion agenda, and these changes must occur in all areas, including teaching, learning, assessment and student support (George and Hicks, 2000; Cuthbert, 2006). 
In an attempt to increase student retention and success in the light of student diversity, inclusive learning and teaching should be a priority for HEls. Guidance shows that the way in which institutions engage with disabled students makes a difference not only to the student learning experience but also to the institution as a whole. Engaging disabled students is particularly key in shaping curriculum and assessment design, as well as the services provided by institutions (ECU and HEA, 2010). Furthermore, if student needs are recognised and anticipated through offering a choice of assessment and feedback methods as standard practice, this may reduce the need for individual case-by-case adjustments (ECU, 2010).

When designing inclusive courses, it may be useful to draw on the constructivist view of learning in order to develop materials that have the best chance of engaging as many students (disabled and non-disabled) as possible. For example, it is helpful to put the material to be learnt into context so that students can relate the new knowledge to their existing knowledge and to their own personal reality. It is also important to assist the students in developing an awareness of their own learning needs so that they are able to recognise the conditions under which they are most likely to learn efficiently.

Current research and advancements in assistive technology should inform the development and enhancement of academic courses and teaching and learning methods. For example, digital and mobile technologies have not traditionally been used for assessment methods. However, research shows that using digital technologies in education not only brings inclusion benefits but also helps with student retention as it offers flexible and innovative ways to learn (JISC, 2012). Mobile learning can enhance opportunities for all, but by enabling students to access content wherever and whenever they want using a device they are happy operating, it also helps to remove the additional barriers that are faced by learners with specific needs (JISC, 2012).

Disabled learners have highly individualised learning needs. As a result, self-regulation and learner autonomy are important aspects of their academic development, and should be facilitated through their learning environment. Assessment feedback strategies can help to encourage learner autonomy, and due to the varying needs of disabled learners, these strategies must be put in place as early as possible. Feedback helps students learn how to improve their work and this in turn will have an impact on their motivation. The learning benefits of feedback are not always brought to fruition, and this may be due to the fact that 
many students are not fully processing the feedback they are given and therefore not learning from it (HEFCE, 2007). Furthermore, feedback from tutors has a direct impact on student satisfaction (HEFCE, 2007).

Price et al. (2010) state that in order for students to benefit from feedback as a 'feed forward' process, they need to be able to understand and engage with it. If students cannot access the feedback in a manner in which they are able to absorb it, then they will not be able to benefit from it. Dyslexic students being provided with written feedback is a prime example, as many (though not all) have difficulties with absorption of information, reading accuracy and word recognition. If they struggle to engage with the feedback then they will be less able to use this to consolidate and enhance their learning. Providing feedback through audio channels may overcome this barrier.

Providing feedback as an audio file of the tutor's spoken comments has several advantages over providing written feedback, and asking the student to use text-to-speech software to access it. Hearing the intonation and inflection in the lecturer's voice may help the student understand the feedback and get a better idea of the key messages to be taken from the comments. Written and spoken comments will differ in style and having a recording of the lecturer's thoughts and ideas as they are marking the assignment adds a personal element, which may increase the level of engagement the student has with the feedback, thus impacting positively on their understanding and learning.

Ice et al. (2007) compared embedded asynchronous audio feedback with asynchronous text only feedback, and found that audio feedback was more effective in several areas. It was found to be more effective for conveying nuance, it was associated with increased feelings of student involvement, it increased retention of content, and it gave the students the perception that the tutor cared more. Furthermore, data revealed that students were three times more likely to apply content from audio feedback than they were for text based feedback (Ice et al., 2007). The authors also found that the time it took tutors to provide audio feedback was $75 \%$ less than when providing text based feedback, a fact likely to encourage academic tutors to adopt the strategy. Furthermore 'this reduction in time was coupled with a 255\% increase in the quantity of feedback provided' (Ice et al., 2007, p.19). Bunyan et al. (2008) also found that audio feedback increased both the quantity and the quality of feedback provided to students. 
Merry and Orsmond (2008) carried out a study into the effectiveness of providing students with audio feedback and they found that students not only perceive but also put into practice the feedback in more meaningful ways than written feedback. Other research has examined how audio feedback is an improvement on written feedback (JISC) and has revealed that benefits include communicating on a more personal level with the student, motivating students, informing students how to improve, the ability to use tone, encouraging students to listen to all of the feedback rather than selecting sections they wish to engage with, and providing an alternative to what is often illegible handwriting (JISC, 2013).

The benefits of audio feedback can be understood in relation to Mayer's Multimedia Theory of Learning. 'People learn more deeply from words and pictures than from words alone' (Mayer, 2001, p.47) but humans can only process a finite amount of information through the two information processing channels (auditory and visual) at a time (Sweller's theory of cognitive load; Sweller, 1988). Mayer's theory works on the basis that the brain interprets multimedia elements dynamically by selecting and organising to produce logical mental schema. Audio feedback can help learning by reducing the load on a single processing channel and allowing active filtering and integrating of information based on prior knowledge. It therefore follows that this method of feedback would be beneficial to all students, and will increase access for some disabled students.

Providing audio feedback is just one approach to make courses more inclusive and accessible to students, and it is our responsibility as educators to adapt and mold our approaches to teaching and learning in line with changing student needs. Although this area would benefit from further research, there is strong evidence supporting the educational benefits of audio feedback for students in terms of engaging the student, increasing their learning, and improving accessibility to tutor comments. Audio feedback is an adaptive and highly effective way of delivering tutor comments to students, as the more input channels that are used (e.g. written, audio, visual) the better the student engages with the information. This has an impact on success and retention, as well as quality of learning and improvement. 


\section{References}

Bunyan, N., King, D. and McGugan, S. (2008) 'Does it make a difference? Replacing text with audio feedback', Practice and Evidence of Scholarship of Teaching and Learning in Higher Education, 3(2), pp. 125-163.

Cuthbert, R. (2006) 'Widening participation in higher education through the scholarship of teaching and learning', $6^{\text {th }}$ Scholarship of Teaching and Learning Conference. London 18-19 May.

Equality Challenge Unit (ECU) (2010) Managing reasonable adjustments in higher education. Available at: http://www.ecu.ac.uk/publications/files/managingreasonable-adjustments-in-higher-education.pdf/view (Accessed: 13 July 2012).

Equality Challenge Unit (ECU) and Higher Education Academy (HEA) (2010) Strategic approaches to disabled student engagement. Available at:

http://www.ecu.ac.uk/publications/strategic-approaches-to-disabled-studentengagement (Accessed: 31 July 2012).

George, R. and Hicks, M. (2000) 'Changing context, changing practice: managing change in student support services', ASET HERDSA Conference. University of Southern Queensland, Toowoomba 2-5 July [Online]. Available at:

http://www.ascilite.org.au/aset-archives/confs/aset-herdsa2000/procs/george1.html (Accessed: 16 July 2012).

HEFCE (2007) The National Student Survey 2005-2007 findings and trends. Available at: https://www.hefce.ac.uk/data/year/2008/thenationalstudentsurvey20052007findingsandtrends/ (Accessed: 1 July 2013).

HESA (n.d.) PIs: widening participation of students in receipt of DSA (table T7). Available at:

http://www.hesa.ac.uk/index.php?option=com content\&task=view\&id=2062\&/temid =141 (Accessed: 1 July 2013). 
Ice, P., Curtis, R., Phillips, P. and Wells, J. (2007) 'Using asynchronous audio feedback to enhance teaching presence and students' sense of community', Journal of Asynchronous Learning Networks, 11(2), pp. 3-25.

JISC (2012) How can digital technologies help my institution recruit a wider mix of students? Available at:

http://www.jisc.ac.uk/supportingyourinstitution/studentjourney/wideningparticipation. aspx (Accessed: 17 July 2013).

JISC (2013) Using audio feedback for assessment. Available at: http://www.jiscdigitalmedia.ac.uk/guide/audio-feedback (Accessed: 1 August 2013).

Mayer, R.E. (2001) Multimedia learning. New York: Cambridge University Press.

Merry, S. and Orsmond, P. (2008) 'Students' attitudes to and usage of academic feedback provided via audio files', Bioscience Education, 11, pp. 1-11.

Price, M., Handley, K., Millar, J. and O’Donovan, B. (2010) 'Feedback: all that effort, but what is the effect?' Assessment and Evaluation in Higher Education, 35(3), pp. 277-289.

Scott, I. (2006) 'SoTL in practice in a developing country: how practical can SoTL be in improving the graduate output of higher education?', $6^{\text {th }}$ Scholarship of Teaching and Learning Conference. London 18-19 May.

Sweller, J. (1988) 'Cognitive load during problem solving: effects on learning', Cognitive Science, 12(2), pp. 257-285.

\section{Author details}

Sue is currently working as a Senior Needs Assessor in Cardiff Metropolitan University Assessment Centre. Her role involves assessing students in receipt of Disabled Students Allowance and making recommendations for study skills and technology support. Prior to this Sue has worked in e-learning, developing online learning 
modules, and also taught academic skills and carried out research in teaching and learning in higher education. Sue has a PhD in Cognitive Psychology and has extensive experience of teaching psychology at many levels. Her research interests include the psychological processes involved in learning, learner engagement, and e-learning. Sue is currently developing interests in needs assessment and how assistive technologies can enhance learning for students with disability. Sue is also a fellow of the Higher Education Academy. 